\title{
Information Interaction in Scientific Knowledge
}

\author{
Elena Borisovna Ivushkina
}

Olga Sergeyevna Buryakova

Nellie Igorevna Morozova

Zhanna Viktorovna Gornostaeva

Stepan Anatolyevich Buryakov

Institute of services industry and businesses (branch) of the Don state technical university

\section{Doi:10.5901/mjss.2015.v6n6s3p66}

\section{Abstract}

The information exchange in scientific knowledge, which is characterized by a set of possible results - the reason of all changes happening in science. Information chaos and order act as fundamental elements of the process of information exchange in scientific knowledge. Implementation of information exchanges is one of the main functions of a wide area information network of Internet. The open communications of scientists self-regulated based on their personal choice are a form of information exchange. The internet is universal space in which data from scientific researches are integrated. Any researcher can place information on own opening, experiments in a network, to find adherents, colleagues and colleagues, having integrated with which will achieve success. Practice and culture of communication on Internet, creation of virtual communities, clubs, any working groups - here a new basis of revival of social institutes, in particular, scientific.

Keywords: Information, information field, information exchange, science.

\section{Introduction}

Development something including sciences is interaction, the interrelation of the chaotic and arranged processes. Therefore as fundamental elements of the process of information exchange in scientific knowledge information chaos and order act.

The order and chaos in the modern scientific picture of the world, which are fundamental elements, not only do not exclude each other, and interact among themselves. After all the science represents infinitely developing a direction that corresponds to the principle of the ratio of randomness and orderliness.

The wide area information network of Internet realizes today's era - the complex system saturated with various information exchanges. The open communications of scientists self-regulated based on their personal choice are a form of information exchange. The internet is universal space in which data from scientific researches are integrated. Any researcher can place information on own opening, experiments in the Network, to find adherents, colleagues and colleagues, having integrated with which will achieve success. "The culture of the Internet is implanted in tradition of joint occupation by science, acquisitions of reputation due to high scientific achievements, the critical analysis of work of colleagues and openness of all results of scientific researches with rendering due trust to authors of each of opening" (Kastels, 2004, p. 56-57). During information era of Internet for scientific figures is one of the instruments of professional activity.

\section{Theoretical Basis of Research}

The theoretical foundation of the conducted research is some attempts at the specification of concepts information, information field, and information exchange.

In the context of our research, we suggest considering information as the immanent property of information field of science, which will transform information exchange of chaos and order in scientific knowledge.

We will understand space (area) of scientific knowledge in which information exchange of chaos and order is 
implemented as information field.

The given definitions of information and information field assume the presence of the sender and receiver of information, i.e. it is about some interaction with objects. As information exchange, it is necessary to understand any interaction between objects in the information field of science in the course of which one gets some information, and another does not lose it.

The wide area information network of Internet is common information space, the projection of real space in which the telecommunication and information networks existing today are integrated. It defines technology component of Internet. In the context of problem of information exchange in science of Internet it should be taken into account as uniform information field (space, Wednesday), set of all existing information and knowledge with which the mankind operates.

With the development of information technologies ways of exchange and redistribution of information, that promotes evaluation of the ideas of the world existing earlier change. Naturally, the new historical paradigm is a consequence of information revolution. Throughout long time was considered that the computer is intended producing the artificial reason exceeding human reason. However, today it becomes clear that the purpose of development of computer technologies are communications using computer networks.

Today Internet is considered not simply as the technical tool used in the different purposes but as special ontological reality (Modern philosophical problems natural, technical and social humanities: the textbook for graduate students and competitors of academic degree of the candidate of Science, 2006, p. 460). Development of the Internet network has laid the foundation for considerable changes in mass consciousness. In the representation of many modern researchers, the semantic space of Internet is comparable to chaos in its essentially new understanding - as the structure hiding in itself order. In The internet, information is not chaotic, and structured and united in whole. However, combinations of information are the cornerstone not the principles of linearity, centralization, and hierarchy, but the principles of multidimensionality, non-hierarchy and absence of the semantic center. Starting point, or kernel, the user who can move in any direction acts and create round himself the semantic world based on own choice. With the use of Internet the huge choice of information services and products opens, and the person can organize the information field depending on own requirements. It acts as the evidence of democratization of information public life. At the same time, the considerable share of society has no possibility of connection to The Internet that automatically limits her representatives in further public functioning and development.

Internet transformed the culture of communication between people in general.

The increasing tendencies of distribution of Internet, forming of open space, transformation of the personality in Internet society, designing new social the practical and communication elements, virtualization of social institutes, - all these and other factors in many respects cause structure of information field that is under construction in the virtual plane and deforms traditional means of communication in Internet-means.

The change of types of communication connected with dominance of the visual beginning in broadcast of information suggests idea that the humankind moves to the line of external simplicity in culture, being exempted thereby from surplus and complexity of the valuable and semantic baggage of civilization, which is saved in centuries. The attention of scientists is drawn also by such problems as avarice and fugacity of interpersonal interaction, moving of communication to consciousness area by means of immersion of the person in virtual reality and replacement from his consciousness of vital values.

The information and communicative space of the modern sociocultural system are the characteristic of network culture, which develops spontaneously and spontaneously. At the heart of network culture - differently level contacts of people, their nonlinear interactions. The network culture is the culture created both on knowledge and on virtual and mythological consciousness.

In work of Astafeva O.N. "The synergy discourse of modern information and communicative processes" (Astafyeva, 2004, p. 421-422) can be found definition of network culture as special system of structural interactions in culture of information society which formation in many respects contacts special role of information, expansion of the communicative interactions that are carried out by people by means of modern information technologies.

The inclusion of the individual in the process of creation, storage, processing and information transfer makes changes to his imagination, behavior in the real world, expression of emotions, memory development. One of the main negative results of the change of the principles of communicative activity of people in the real world is the destruction of subjectivity.

The humankind aims at distribution on all planet of the single Internet information and communicative network, but everyone tries to create the own world, having become reserved and having limited forms of the sociality.

Communication in the Internet network attracts with neutrality and without appraisal, lack of social effects. On the 
contrary, distribution of the Internet network limits development of active abilities of the person accustoms him to simulation and the person loses the fundamental need for communication. French philosopher of Bodriyar J. has characterized impact on the person of virtual communications as "weakening of grasp real through excess of visibilities true" (Bodriyyar, 2000, p. 121). The author connected attractiveness of virtual communication with a search of the missing measurement reducing the distance between reality and its double (Bodriyyar, 2000, p. 127).

In our opinion, these and many other contradictions illustrate coherence of the modern person over time in which he lives, with a century of bifurcation. Today the Internet network is a global self-organizing system, the spontaneous and expanding hypertext. Creation by the person of this dynamic information and communication environment has marked peculiar beginning in the development of information culture. Change of valuable reference points as it is general social, and the individual is connected with a change of objective and subjective conditions of communication.

Self-reproduction of the information and communicative Internet network assumes synergy interaction of chaos and order, which finds the expression in simultaneous perception, and rejection of information.

As information becomes key goods of the new economy, and the world sinks into the ocean of chaotic information signals, the increasing value acquires essential and exclusive knowledge Bard \& Zoderkvist (2004). For the modern person information, how many it's semantic and context filling represent bigger interest not so much. Therefore, he aims to sort, structure and comprehend the breaking information flows that they became sources of knowledge. Toffler $\mathrm{E}$. writes: "Today not collection of information, and ability to find in all mass of data that is necessary, truly to analyze the eliminated data and timely to bring them to the necessary customer" (Toffler, 2003, p. 358) is put in the forefront. Not less important, than the contents of information, are the ability to process it and to interpret. "Difficulties of our society - and possibilities of "digital eyelid" - impose relevant requirements of certain people. They need to be better educated to survive economically and to succeed socially. They need to have also appropriate moral education to make difficult decisions", - E. Dayson speaks (Dayson, 1998, p. 121).

The modern model of information exchange of chaos and order in science is synergy. According to Synergy model of interaction in the semantic chaos order field accents from the strict opposition of these categories to the representation of chaos as source and the creator of order are displaced. The main requirements for properties of systems for which the synergy modes of functioning are potentially admissible is the following: the system has to be nonlinear, open, in relation to external environment to be in non-equilibrium status, to be affected by fluctuations, which transfer system status from one phase to another.

Expression of synergy model of information exchange of chaos and order in science is the wide area information network of Internet as continuously changing and very complex system, which is constantly improved. The wide area information network of Internet is information space in which in the absence of rigid relationships of cause and effect subjects and objects coexist and interact.

We understand set of the processes of representation, transfer and obtaining scientific information forming the main engine of existence and development of science as scientific communication. Scientists and specialists participate in all processes of scientific communication.

The open communications of scientists self-regulated because of their personal choice are a form of information exchange. The internet is universal space in which data from scientific researches are integrated. Any researcher can place information on own opening, experiments in the Network, to find adherents, colleagues and colleagues, having integrated with which will achieve success. During information era of Internet is one of the instruments of professional activity.

Also, the general information law under which introduction of new elements to a system of scientific communication does not cancel is valid and does not replace old, traditional means. Evolution in scientific communication is carried out by redistribution of functions between types and means of information support.

Growth of popularity of virtual communication is observed, the number of net surfer's increases, the communication quality improves, and there is a large number of new media in the Network. The developed software facilitates information exchange not only in the form of the text but also in the form of audio-and-video series.

New processes, methods and means of scientific and mass communication which appear continuously and are urged to increase efficiency of intellectual activity of the person, will supplement and enrich system of communication, without leading to dying off of the existing its forms.

\section{Methods and Subject Base of Research}

The methodology of research has a complex character that is caused by interdisciplinary of approaches to studying the problem. Philosophical research of chaos and order as implementers of information exchange in science is based on use 
of the whole complex of philosophical and general scientific methods: analytical, phenomenological, principles of objectivity, general communication, contradiction, methods of contrastive analysis and synthesis, scientific generalization. In research were applied the conceptual and logical analysis of theoretical terminology for the purpose of the redefinition of the physical and mathematical term "information" to sociocultural context. To it methods of the historical and genetic analysis of scientific methodology - for the analysis of its reorientation from formal and theoretical installation to socially significant were attracted. The initial methodological idea of research is dialectic approach and the systems concept.

\section{Results of Research}

Means and forms of communication change. The modern person loses ability to live, direct communication since together with the formation of a new type of culture there is also a new kind of subjects of communication. The written and audiovisual systems, which have developed in the XIX-XX centuries, were added to the new system of computer culture that cornerstone interactive interaction is.

The eyelid of natural contacts between people is succeeded by a century of interactive interactions. Despite the infinite increase in some contacts, the person is not always satisfied by semantic fullness and purposes of such communications. As Kagan M. S. has precisely noticed that complication of communications in modern society is necessary to consider their simplification in internal personal space (Kagan, 1997)

New processes, methods and means of scientific and mass communication which appear continuously and are urged to increase efficiency of intellectual activity of the person, will supplement and enrich system of communication, without leading to dying off of the existing its forms.

Researches in the field of digital libraries as one of actual and very attractive directions of development of information exchange in science, creation of digital libraries provides the new level of receiving and generalization of knowledge, their distribution and use. Digital libraries are meant of ensuring of intellectual access to the distributed information warehouses based on the creation of information environments. The digital library provides access to large volumes of the multimedia information and knowledge.

Studying of the mechanism of information exchange in science at change is the actual scientific paradigm. The mechanism of information exchange it is not simple process of information exchange that generates change of knowledge at least of one of the receivers of these data, the specified mechanism causes more profound changes that are characterized by receiving new knowledge, replenishment of the available stock of knowledge in message sink. Principal components, on which information exchange is based on information, information field, chaos, and order.

\section{Conclusions}

Development something including sciences is interaction, the interrelation of the chaotic and arranged processes. Therefore as fundamental elements of the process of information exchange in scientific knowledge information chaos and order act.

Time, in which we live, is characterized by an increase of information component of human life, and this component becomes subject to different scientific interpretations.

From the moment of origin and until the end of the existence all material objects and processes stay in information field which continuously influences them. For science studying of information field - new level in understanding of the person and his opportunities. As a result of the conducted research, we come to the conclusion that the information field of science represents an area of scientific knowledge in which information exchange of chaos and order is implemented. Information exchange we will call the interaction of objects leading to reception or generation of scientific information.

The order and chaos in the modern scientific picture of the world, which are fundamental elements, not only do not exclude each other, and interact among themselves. After all the science represents infinitely developing a direction that corresponds to the principle of the ratio of chaoticity and orderliness. The interrelation of chaos and order in science occurs through information, which, in turn, builds information exchanges in science. It is accepted to select three models of information exchange of chaos and order in science: mechanistic, dialectic, synergy.

The modern model of information exchange of chaos and order in science is synergy. According to Synergy model of interaction in the semantic chaos order field accents from the strict opposition of these categories to the representation of chaos as source and the creator of order are displaced. Expression of synergy model of information exchange of chaos and order in science is the wide area information network of Internet as continuously changing and very complex system, which is constantly improved.

Also, the general information law under which introduction of new elements to a system of scientific communication 
does not cancel is valid and does not replace old, traditional means. Evolution in scientific communication is carried out by redistribution of functions between types and means of information support.

New processes, methods and means of scientific and mass communication which appear continuously and are urged to increase efficiency of intellectual activity of the person, will supplement and enrich system of communication, without leading to dying off of the existing its forms.

\section{References}

Kastels, M. (2004) Galaktika Internet: Reflections about the Internet, business, and society. The lane from English A. Matveev under the editorship of V. Kharitonov. Yekaterinburg: The U-trading station (with the assistance of publishing house of Humanities University). pp. 56-57.

Modern philosophical problems natural, technical and social humanities: the textbook for graduate students and competitors of academic degree of the candidate of science (2006) / under the general edition of the Doctor of Philosophy, Professor V.V. Mironov. M.: Gardarika. pp. 460.

Astafyeva, O.N. (2004) Sinergetichesky discourse of modern information and communicative processes//Synergy paradigm. The cognitive and communicative strategy of modern scientific knowledge. M.: Progress-Tradition. pp. 421-422.

Bodriyyar, Zh. (2000) Temptation / translation from the French A. Garadzhi. Ad Marginem publishing house. Moscow. pp. 121.

Bard, A. \& Zoderkvist, I. (2004) Netokratiya. New ruling elite and life after capitalism: Stockholm school of the economy, Spb. pp. 252.

Toffler, E. (2003) Metamorphoses of the power: The lane with English / E. Toffler. - M.: JSC ACT Publishing House. pp. 358.

Dayson, E. (1998) Zhizn during Internet era. M: Business and computer. pp. 121.

Kagan, M.S. (1997) Estetika as philosophical science. - St. Petersburg, shopping Mall Petropolis LLP. pp. 544. 